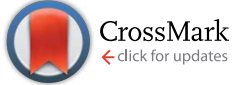

Cite this: RSC Adv., 2016, 6, 33101

Received 22nd January 2016

Accepted 18th March 2016

DOI: 10.1039/c6ra01986b

www.rsc.org/advances

\title{
Highly stable organic-inorganic junction composed of hydrogenated titania nanotubes infiltrated by a conducting polymer $\dagger$
}

\author{
Katarzyna Siuzdak, ${ }^{\text {aa }}$ Mariusz Szkoda, ${ }^{\mathrm{b}}$ Anna Lisowska-Oleksiak, ${ }^{\mathrm{b}}$ Jakub Karczewski ${ }^{\mathrm{c}}$ \\ and Jacek Ryl ${ }^{\text {d }}$
}

A poly(3,4-ethylenedioxythiophene) conducting polymer doped with poly(2-styrene sulfonate) (pEDOT:PSS) was efficiently electrodeposited on a layer composed of ordered titania nanotubes. $\mathrm{TiO}_{2}$ nanotubes were formed during an anodization process and, after calcinations, a layer was subjected to hydrogen plasma. Hydrogenation leads to Ti(II) formation, a decrease in resistance, and a huge increase of donor density when compared with pure titania. According to a detailed structure analysis, the coverage by the polymer matrix is uniform on the entire titania surface as well as along the tubes. The composite material exhibits highly enhanced anodic photocurrent $\left(106 \mu \mathrm{A} \mathrm{cm}^{-2}\right)$ when compared with hydrogenated titania $\mathrm{H}-\mathrm{TiO}_{2}\left(54 \mu \mathrm{A} \mathrm{cm}{ }^{-2}\right)$ or pure polymer film $\left(2 \mu \mathrm{A} \mathrm{cm}{ }^{-2}\right)$. Moreover, $\mathrm{H}-\mathrm{TiO}_{2}$ / pEDOT:PSS is characterized with high photostability displayed during prolonged illumination. The proposed hydrogenation approach could be regarded as a facile titania modification for further electrochemical modifications.

\section{Introduction}

Research into photoactive materials has long aimed at identifying low-cost semiconducting materials and facile preparation of photovoltaic junctions. Among many inorganic semiconductors, titanium dioxide, in particular well-ordered $\mathrm{TiO}_{2}$ nanotubes $\left(\mathrm{TiO}_{2} \mathrm{NTs}\right)$, has attracted a great deal of attention because of its advantages of an efficient pathway for vectorial electron transfer, light propagation through the nanoarchitecture, and a large surface to volume area. ${ }^{1,2}$ The ordered titania nanotubes are formed via electrochemical anodization of Ti plate immersed in fluoride-rich electrolyte. Precise optimization of anodization parameters, such as voltage, process duration, current distribution, temperature, and electrolyte composition, allows control of the morphology of the obtained $\mathrm{TiO}_{2} \mathrm{NT}$ film. ${ }^{3}$

$\mathrm{TiO}_{2}$ nanotubes have replaced $\mathrm{TiO}_{2}$ nanoparticles in many applications because the anodization procedure for the

${ }^{a}$ Centre, for Plasma and Laser Engineering, Szewalski Institute of Fluid Flow Machinery, Polish Academy of Science, Fiszera 14, Gdańsk 80-231, Poland. E-mail: ksiuzdak@imp.gda.pl; Fax: +48 58 3416144; Tel: +48 586995294

${ }^{b}$ Department of Chemistry and Technology of Functional Materials, Chemical Faculty, Gdańsk University of Technology, Narutowicza 11/12, Gdańsk 80-233, Poland

${ }^{c}$ Faculty of Applied Physics and Mathematics, Gdańsk University of Technology, Narutowicza 11/12, 80-233 Gdańsk, Poland

${ }^{d}$ Department of Electrochemistry, Corrosion and Materials Engineering, Gdańsk University of Technology, Narutowicza 11/12, 80-233 Gdańsk, Poland

$\dagger$ Electronic supplementary information (ESI) available. See DOI: 10.1039/c6ra01986b nanotubes is relatively simple and can be highly controlled. As an n-type semiconductor, $\mathrm{TiO}_{2}$ NTs are widely used in sensors, electrochromic devices, ${ }^{4}$ and devices for energy conversion and storage. ${ }^{5}$ In the case of photoconversion devices, titanium dioxide is widely used in dye-sensitized solar cells, inverted organic solar cells as a buffer layer, ${ }^{6}$ and blended with organic sensitizers or donors. ${ }^{7}$ In the $\mathrm{TiO}_{2} /$ polymer-based solar cell, $\mathrm{TiO}_{2}$ forms $\mathrm{p}-\mathrm{n}$ heterojunctions in which the conducting polymer acts as a p-element. Highly ordered heterojunctions obtained by filling metal oxide nanostructure with conducting polymer have distinctive advantages over composites in which nanoparticles are randomly distributed inside polymer because of a more direct and more efficient charge transfer path. ${ }^{8}$ Therefore, there has been intense research on $\mathrm{TiO}_{2} \mathrm{NT} /$ conducting polymer heterojunctions and their applications for photocurrent generation, ${ }^{9}$ water splitting, ${ }^{10}$ and energy storage. $^{\mathbf{1 1 , 1 2}}$ Polyaniline, $^{\mathbf{1 3}}$ polypyrrole, ${ }^{14}$ or poly(3,4-ethylenedioxythiophene $)^{15}$ are used as conducting polymers. In most cases, polymer is formed inside the $\mathrm{TiO}_{2} \mathrm{NTs}$ via electrochemical $^{16}$ or photoelectrochemical polymerization. ${ }^{17}$ Depending on the polymerization conditions (potentiostatic, potentiodynamic) and titania morphology, polymer matrix can be introduced inside the tubes or deposited on the outer wall. ${ }^{18}$ Furthermore, there have also been some attempts to facilitate and make deposition of polymer more uniform. Mainly, these involve titania modification by silane derivatives ${ }^{\mathbf{1 9}}$ or electrode illumination during the polymerization process ${ }^{\mathbf{1 6}}$ (photoelectrochemical polymerization). However, titania nanotubes obtained by anodization have fairly high resistance, which 
hampers direct electrodeposition of conducting polymer, and, additionally, an insulating barrier layer is present between titanium metal plate and tubular nanostructure. ${ }^{20}$ Recently, hydrogenation treatment was proposed to achieve improved conductivity of $\mathrm{TiO}_{2}$, and ultimately to achieve effective polymer deposition. ${ }^{21}$ According to the literature reports, $\mathrm{TiO}_{2}$ treatment in hydrogen atmosphere enhances electrochemical activity and conductivity because of increased donor density and introduction of surface hydroxyl groups. ${ }^{22,23}$ Thus, such an approach could lead to activation of the titania surface to allow for further electrochemical modifications.

This paper focuses on formation of composite material containing ordered titania nanotubes infiltrated with conducting polymer: pEDOT:PSS. Titanium nanotubes were formed on titanium foil via anodization in fluoride-rich electrolyte, followed by calcination to obtain the crystalline phase of the materials. Anatase NTs were subjected to hydrogen plasma to activate the surface for further polymer deposition. Polymer was introduced inside the nanostructure by potentiostatic electro-

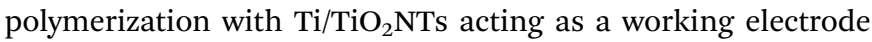
immersed in monomer and counter ion solution. The morphology, crystal structure, and composition were investigated using scanning electron microscopy, Raman, UV-Vis, and $\mathrm{X}$-ray photoelectron spectroscopy techniques. Electrochemical activity of the composite electrode, as well as pure and hydrogenated titania, was tested by means of cyclic voltammetry and electrochemical impedance spectroscopy measurements. To verify the stability of the $\mathrm{TiO}_{2} \mathrm{NTs} /$ polymer junction under illumination, long transient photocurrent measurements were performed.

\section{Experimental}

\section{Preparation of hydrogenated $\mathrm{TiO}_{2}$}

The $\mathrm{TiO}_{2} \mathrm{NT}$ samples were prepared via two-step anodization according to a previously optimized procedure. ${ }^{24}$ Before anodization, the substrate sample (Ti plate, Steam, 99.7\%) was ultrasonically cleaned, with acetone, ethanol, and water, in that order, for 10 minutes in each solvent, and ultimately dried in air. The process was realized in a two-electrode configuration at room temperature, in which the titanium plate served as an anode and the platinum mesh as a cathode with a fixed distance of $2 \mathrm{~cm}$ between them. The first anodization took place in electrolyte containing ethylene glycol (EG), $0.27 \mathrm{M} \mathrm{NH}_{4} \mathrm{~F}$, and 1 vol\% of deionized water. Anodization was performed at $40 \mathrm{~V}$ for $2 \mathrm{~h}$, with an initial voltage rate of $0.1 \mathrm{~V} \mathrm{~s}^{-1}$, then the titanium plate was immersed for $12 \mathrm{~h}$ in $0.5 \%$ wt solution of oxalic acid to remove the rugged nanotube layer. The second anodization process was performed on the as-cleaned titanium plate under the same conditions as those during the first anodization. To remove surface debris, the titanium plates covered with nanotubes were immersed in $0.05 \%$ wt HF for $180 \mathrm{~s}$. After the second anodization, the samples were rinsed with deionized water, dried in air, and thermally treated at $450{ }^{\circ} \mathrm{C}$ for $2 \mathrm{~h}$ with a heating rate of $2{ }^{\circ} \mathrm{C} \min ^{-1}$ to transform the amorphous $\mathrm{TiO}_{2}$ into a crystalline phase.
Finally, the $\mathrm{TiO}_{2} \mathrm{NTs}$ were subjected to a hydrogen environment in a plasma reactor (Electronic Diener) operating at a power of $40 \mathrm{~W}$, at room temperature, for $60 \mathrm{~min}$. The obtained sample was coded as $\mathrm{H}-\mathrm{TiO}_{2} \mathrm{NTs}$.

\section{Fabrication of $\mathrm{H}-\mathrm{TiO}_{2} \mathrm{NTs} / \mathrm{PEDOT}-\mathrm{PSS}$}

Electrochemical polymerization was carried out to prepare $\mathrm{H}-$ $\mathrm{TiO}_{2}$ NTs/PEDOT:PSS. After a series of optimization experiments, electrochemical deposition was performed in an aqueous solution containing 0.1 M NaPSS and 0.001 M EDOT, by potentiostatic polymerization of $1.6 \mathrm{~V} v s . \mathrm{Ag} / \mathrm{AgCl} / 0.1 \mathrm{M} \mathrm{KCl}$ consuming charge of $30 \mathrm{mC} \mathrm{cm}^{-2}$. The hydrogenated titania sample constituted a working electrode. The reference electrode was $\mathrm{Ag} / \mathrm{AgCl} / 0.1 \mathrm{M} \mathrm{KCl}$, and a platinum mesh was used as a counter electrode. Finally, the working electrode was washed with deionized water and dried in air.

\section{Characterization}

The surface morphology and cross-section were examined using the Schottky field emission scanning electron microscope (FEI Quanta FEG 250) with an ET secondary electron detector. The beam accelerating voltage was kept at $10 \mathrm{kV}$. For elemental analysis, energy dispersive X-ray spectroscopy (EDX) was performed using an EDAX Genesis APEX 2i with ApolloX SDD spectrometer on a particular area of each sample. To confirm uniform polymer deposition, elemental analysis was completed on the surface and across the composite layer. The chemical nature of elements and binding properties of the surface were studied by X-ray photoelectron spectroscopy (XPS), using the Escalab 250Xi from ThermoFisher Scientific. High-resolution spectra were recorded at an energy step size of $0.1 \mathrm{eV}$ at a pass energy of $10 \mathrm{eV}$. To normalize the spectroscopic measurements, the $X$ axis (binding energy, $E_{\mathrm{bin}}$ ) of the XPS spectrum was calibrated for peak characteristics of neutral carbon $1 \mathrm{~s}\left(E_{\mathrm{bin}}=284.6 \mathrm{eV}\right)$. UV-Vis reflectance spectra of titania nanotubes were measured with a dual beam UV-Vis spectrophotometer (Lambda 35, PerkinElmer) equipped with a diffuse reflectance accessory. The spectra were registered in a range of 300-700 nm, with a scanning speed of $60 \mathrm{~nm} \mathrm{~min}{ }^{-1}$. Bandgap energy values were determined as the intercept of the tangent of the plot of transformation of the Kubelka-Munk function. This method was used to determine the bandgap energy for pure and $\mathrm{H}-\mathrm{TiO}_{2}$ NTs. Raman spectra were recorded using a confocal micro-Raman spectrometer (InVia, Renishaw) with sample excitation, by means of an argon ion laser emitting at $514 \mathrm{~nm}$ operating at $5 \%$ of its total power $(50 \mathrm{~mW})$.

\section{Electrochemical and photoelectrochemical measurements}

Electrochemical measurements were carried out using an AutoLab PGStat 302N potentiostat-galvanostat system (Methrom, Autolab) in the standard three-electrode assembly, with titanium foil covered by nanotubes serving as the working electrode (active surface area of $0.3 \mathrm{~cm}^{2}$ ). Electrodes were tested in contact with deaerated aqueous $0.5 \mathrm{M} \mathrm{K}_{2} \mathrm{SO}_{4}$ electrolyte. An electrochemical cell was equipped with a quartz window. The photoactive layers were illuminated with a $150 \mathrm{~W}$ Xenon lamp 
(Osram XBO 150) and an AM 1.5 filter was used to obtain simulated solar light. An automated light chopper with a period of $90 \mathrm{~s}$ was used as a light source. The irradiance of incident light was measured to be $100 \mathrm{~mW} \mathrm{~cm}^{-2}$ using a reference cell (Si solar cell, Rera). The photocurrent measurements were carried out at $+0.5 \mathrm{~V}$ vs. $\mathrm{Ag} / \mathrm{AgCl} / 0.1 \mathrm{M} \mathrm{KCl}$ bias voltage. To perform measurements under the visible light range, an additional cutoff optical filter $(\lambda>420 \mathrm{~nm})$ was added to the experimental setup.

Electrochemical impedance spectroscopy (EIS) measurements for titania as well as composite samples were conducted at a frequency range between $20 \mathrm{kHz}$ and $0.1 \mathrm{~Hz}$, covering 75 points and with $10 \mathrm{mV}$ amplitude of the AC signal. To perform the Mott-Schottky analysis, impedance spectra were recorded at different potentials in the range between $+0.9 \mathrm{~V}$ and $-0.6 \mathrm{~V} v s$. $\mathrm{Ag} / \mathrm{AgCl} / 0.1 \mathrm{M} \mathrm{KCl}$. Before each spectrum registration, the potential was held to achieve a steady state condition. The impedance data were analyzed on the basis of an electric equivalent circuit (EEQC) using an EIS spectrum analyzer program.

\section{Results and discussion}

\section{Characterization}

Scanning electron microscopy was employed to investigate the surface morphology of $\mathrm{H}-\mathrm{TiO}_{2} \mathrm{NT}$ and composite $\mathrm{H}-\mathrm{TiO}{ }_{2} \mathrm{NTs} /$ pEDOT:PSS. Fig. 1a and $\mathrm{b}$ shows the top-view and crosssection SEM images of pure and $\mathrm{H}-\mathrm{TiO}_{2} \mathrm{NTs}$ layer, respectively. The obtained nanotubes were ordered and aligned. When comparing the SEM images registered for both materials, no difference was observed in the nano-architecture between the hydrogenated and pure titania. This suggests clearly that the applied plasma treatment did not influence the morphology, and only potential changes in the chemical states could have an
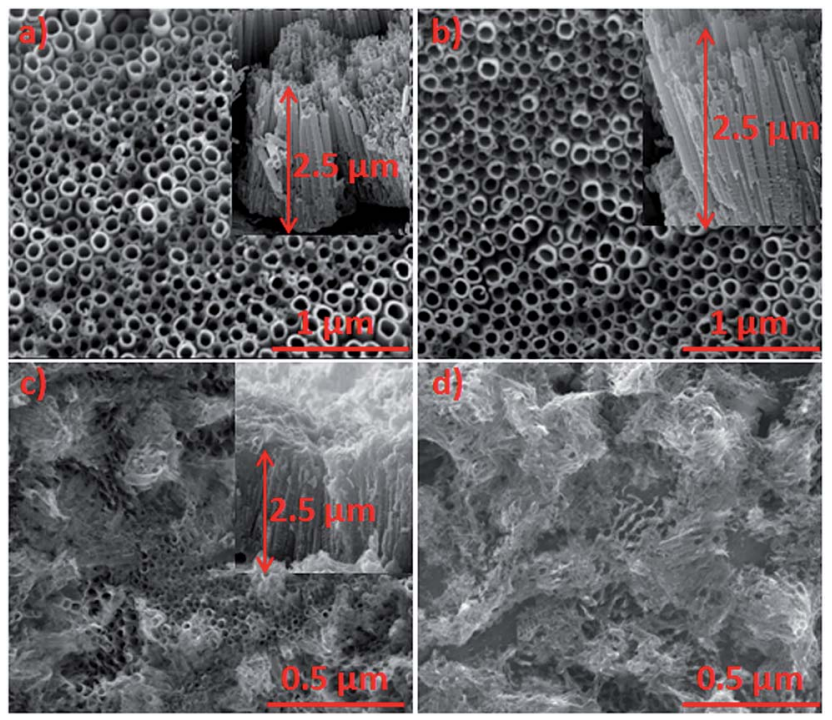

Fig. 1 SEM images of (a) pure $\mathrm{TiO}_{2}$, (b) hydrogenated $\mathrm{TiO}_{2}$, (c) $\mathrm{H}-$ $\mathrm{TiO}_{2} \mathrm{NTs} / \mathrm{pEDOT}$ :PSS composite material, (d) remaining pEDOT:PSS after $\mathrm{H}-\mathrm{TiO}_{2}$ removal. impact on the electrochemical properties of titania. High resolution images allowed determination of tube dimensions: internal diameter of $100 \mathrm{~nm}$, a tube-wall thickness of $25 \mathrm{~nm}$, and tube length of $2.5 \mu \mathrm{m}$. Fig. 1c shows the layer of titania nanotubes infiltrated with pEDOT:PSS. The images demonstrate the growth of polymer film on the surface as well as along the tubes. In some cases, the holes are entirely filled with pEDOT:PSS matrix. This type of layer growth allows for close metal oxide-polymer contact, which is required in $\mathrm{p}-\mathrm{n}$ heterojunction photovoltaic cells.

To determine the location of deposited polymer, the obtained composite $\mathrm{H}-\mathrm{TiO}_{2} \mathrm{NTs} / \mathrm{pEDOT}$ :PSS was immersed in diluted hydrofluoric acid $(0.5 \mathrm{M})$, which selectively dissolves $\mathrm{TiO}_{2}$ nanotubes. ${ }^{25}$ The efficiency of crystalline titania form removal was highlighted by the Raman spectrum in which no bands typical for anatase were registered. After removal of the titania network acting as polymer scaffolding, pEDOT:PSS collapses and does not retain the ordered structure (see, Fig. 1d). The observed shape of remaining polymer allows us to conclude that polymerization takes place both inside and inbetween nanotubes, as previously observed by Janáky et al. ${ }^{\mathbf{2 6}}$

Energy dispersive X-ray spectroscopy was used to study distribution of the polymer matrix over the titania surface and along the tubes. Fig. S1a-c $\dagger$ shows clearly that the distribution of elements (C, O, S) included in pEDOT:PSS is homogeneous. Therefore, the material composition was preserved when the sample was investigated at its surface. The atomic content of each element present in the composite sample is as follows: Ti: 33.04 at\%; O: 51.23 at\%, C: 15.01 at\%, S: 0.36 at\%. As it is known that the polymer also contains oxygen atoms, the titanium to oxygen ratio deviates from $\mathrm{TiO}_{2}$ stoichiometry suggesting an oxygen deficit in the inorganic semiconductor. Furthermore, local EDX analysis performed at nine different points across composite materials (see Fig. S2 $\dagger$ ) showed uniform distribution of sulfur that builds pEDOT:PSS, and oxygen and carbon species present in the polymer and titania material. Thus, it is suggested that polymer penetrates the free space in the titania nanostructure from the surface region down to the tube base. However, as EDX inspection is characterized by limited resolution, further investigations using XPS were carried out under the etching mode allowing more valuable analysis.

The Raman spectra recorded for composite material and its pure counterparts, hydrogenated titania nanotubes and conducting polymer, are shown in Fig. 2. Raman spectra for unmodified titania nanotubes are given as a reference. A number of bands characteristic of the pure anatase crystalline form of $\mathrm{TiO}_{2}$ were identified in samples of pristine titania and composite material. The bands located at 144, 198, 395, 516, and $637 \mathrm{~cm}^{-1}$ are attributed to $\mathrm{E}_{\mathrm{g}(1)}, \mathrm{E}_{\mathrm{g}(2)}, \mathrm{B}_{1 \mathrm{~g}}, \mathrm{~A}_{1 \mathrm{~g}}$, and $\mathrm{E}_{\mathrm{g}(3)}$ active anatase modes, respectively. ${ }^{27,28}$ Characteristic bands of pEDOT:PSS are observed in pure polymer and composite material. The main band at $1433 \mathrm{~cm}^{-1}$ can be attributed to symmetric $(\mathrm{C}=\mathrm{C})-\mathrm{O}$ bond vibrations in the thiophene ring. Two peaks at $1495 \mathrm{~cm}^{-1}$ and $1561 \mathrm{~cm}^{-1}$ could be interpreted as asymmetric $\mathrm{C}=\mathrm{C}$ modes in polymer chains. ${ }^{29}$ The peaks 1366 and $1267 \mathrm{~cm}^{-1}$ are characteristic of vibrations of single-bonded 

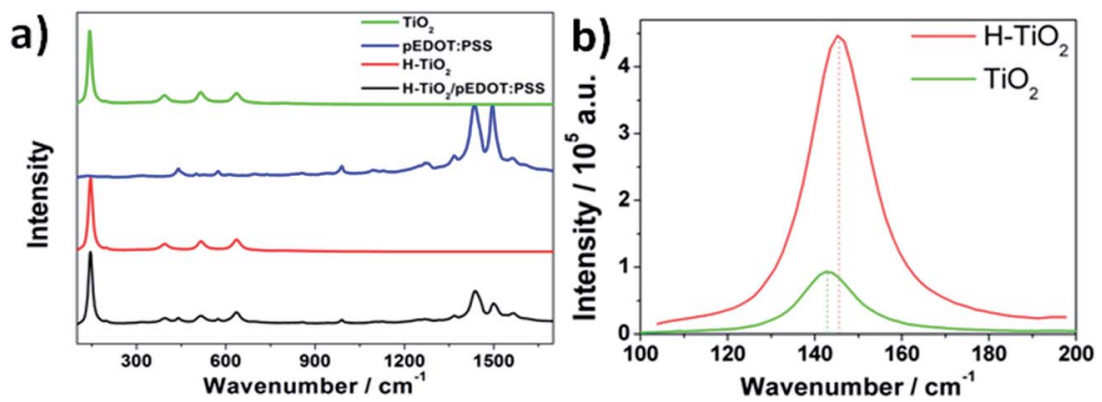

Fig. 2 (a) Raman spectra of pristine and hydrogenated titania, pEDOT:PSS film, and composite material, (b) closer view of the E $\mathrm{g}_{(1)}$ peak for pristine and hydrogenated $\mathrm{TiO}_{2}$.

carbon atoms in the polymer chain and in the thiophene ring, respectively. The oxyethylene ring deformations can be identified at 988, 571, and $442 \mathrm{~cm}^{-1} .{ }^{30}$ The Raman spectra registered for the pure titania and hydrogenated sample are very similar. This indicates that the material has not changed significantly during the plasma treatment. However, as shown in Fig. 2b, a slight shift is observed of the $\mathrm{E}_{\mathrm{g}(1)}$ maximum of $143.3 \mathrm{~cm}^{-1}$ registered for pure $\mathrm{TiO}_{2} \mathrm{NTs}$ to $145.7 \mathrm{~cm}^{-1}$ for $\mathrm{H}-\mathrm{TiO}_{2} \mathrm{NTs}$. This shift can be attributed to the increased number of oxygen vacancies in $\mathrm{H}-\mathrm{TiO}_{2} \cdot{ }^{31}$ Furthermore, a closer view of the Raman spectra reveals that the $E_{g(1)}$ peak of hydrogen plasma-treated titania is broadened compared with that of pure $\mathrm{TiO}_{2}$. The spectral broadening is suggested to arise from modification ${ }^{32}$ of the crystal lattice resulting from oxygen vacancy, as oxygen vacancy defects are known to have a role in absorption of $\mathrm{O}_{2}$ molecules or can act as electron scavengers leading to retardation of charge recombination. The intensity of the anatase signal $\mathrm{E}_{\mathrm{g}(1)}$ of the $\mathrm{H}-\mathrm{TiO}_{2} \mathrm{NTs}$ is also much higher than that of pure $\mathrm{TiO}_{2}$, suggesting that the crystal size of $\mathrm{TiO}_{2}$ may be increased by hydrogen plasma treatment. ${ }^{33,34}$ According to Samsudin et al. ${ }^{34}$ however, $\mathrm{Ti}^{3+}$ and oxygen vacancies have larger roles in the improved electrical properties of hydrogenated titania than do surface disorder or change in crystal size created during the hydrogenation process.

UV-Vis spectroscopy was also used to characterize the optical properties of the obtained materials, and to determine the energy bandgap for $\mathrm{H}-\mathrm{TiO}_{2}$ and $\mathrm{TiO}_{2}$ nanotubes. Fig. 3a and b shows the absorbance curves and the plot of Kubelka-Munk function vs. photon energy. Typical absorption in the UV region, ${ }^{35}$ the broad band in the range of $400-600 \mathrm{~nm}$, was registered for both pure and $\mathrm{H}-\mathrm{TiO}_{2} \mathrm{NTs}$, but the absorbance ability of hydrogenated titania is much higher compared with that of pure $\mathrm{TiO}_{2}$. The values of $E_{\mathrm{bg}}$ determined on the basis of the Tauc plot are 3.08 and $2.98 \mathrm{eV}$ for pure and $\mathrm{H}-\mathrm{TiO}_{2} \mathrm{NTs}$, respectively. The narrowing of bandgap energy was discussed in detail by Wang et al.: ${ }^{36}$ upon hydrogenation, the titania disorder shell loses lattice periodicity and breaks the octahedral symmetry of $\mathrm{TiO}_{6}$, with formation of a tail of the conduction band $(\mathrm{CB})$, which leads to bandgap narrowing. Surface defects and reconstruction in titania nanocrystals lead to strong band tailing near the CB edge, whereas hydrogen atoms introduce localized states below the CB minimum. To summarize, enhanced absorbance in a visible region results from electronic transitions from the tailed conduction band, localized states of oxygen vacancies, and from mid-gap electronic states to the conducting band.

For the pEDOT:PSS modified sample, a broad and intensive band between 500 and $700 \mathrm{~nm}$ is observed, resulting from the presence of polymer matrix. ${ }^{37}$ The increase in the absorbance ability of heterojunction in the visible range results from occurrence of $\pi-\pi^{*}$ transitions ${ }^{38}$ in the oxidized polymer matrix. The run of the absorbance curve registered for $\mathrm{H}-\mathrm{TiO}_{2} \mathrm{NTs} /$ pEDOT:PSS indicates that the composite material should exhibit better photoactivity under visible light than its pure counterparts, therefore, it is especially useful for application in photovoltaic cells. A change in absorbance properties exhibited
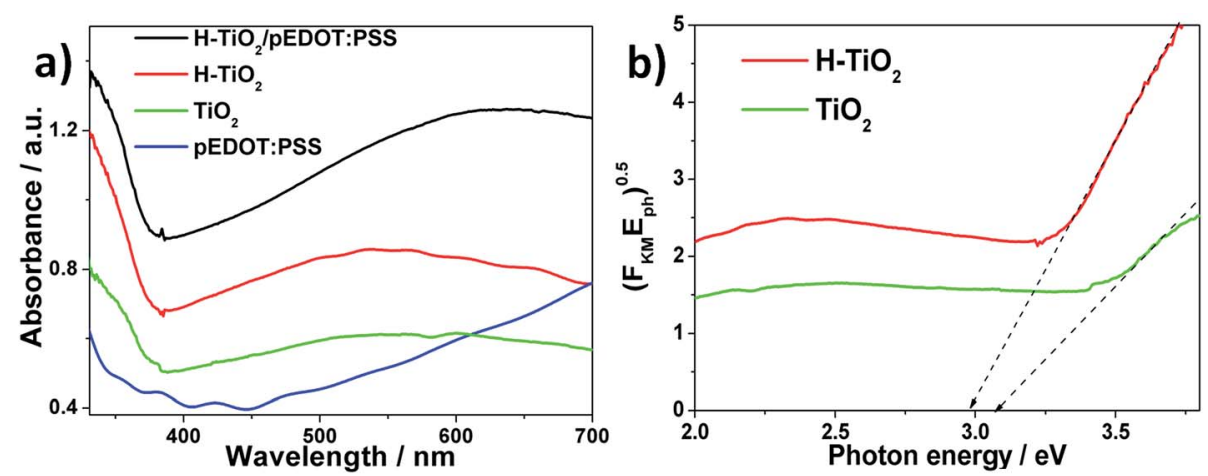

Fig. 3 (a) Absorbance spectra for titania nanotubes and composite material, (b) the Tauc plot for pure and hydrogenated $\mathrm{TiO}_{2} \mathrm{NTS}_{\mathrm{S}}$ 
after polymer deposition is also clearly visible in the deep blue colour of the composite material (see Fig. S3†).

To investigate the change in the chemical state of elements on hydrogen plasma treatment, X-ray photoelectron spectroscopy measurements were performed. The XPS spectra recorded for titanium, oxygen, and carbon regions of hydrogenated titania are shown in Fig. 4, and Table 1 gives the position of each spectrum maximum. The respective spectra found for pure titania were described in our previous report. ${ }^{39}$ In contrast to unmodified $\mathrm{TiO}_{2}$, the region attributed to titania for $\mathrm{H}-\mathrm{TiO}_{2}$ is characterized as two doublets containing both Ti2 $\mathrm{p}_{1 / 2}$ and Ti2 $\mathrm{p}_{3 / 2}$ signals. The highest maximum located at $459.07 \mathrm{eV}$ is attributed to $\mathrm{Ti}(\mathrm{Iv})$ in anatase crystalline phase. ${ }^{40}$ However, this value is shifted by $0.29 \mathrm{eV}$ when compared with the respective peak recorded for pure titania. The small peaks at $457.20 \mathrm{eV}$ for Ti2 $\mathrm{p}_{3 / 2}$ and $462.62 \mathrm{eV}$ for Ti2 $\mathrm{p}_{1 / 2}$ result from the existence of $\mathrm{Ti}(\mathrm{III}) .{ }^{41}$ The relation between the atomic content of $\operatorname{Ti}(\mathrm{IV})$ and $\mathrm{Ti}$ (III) is $14.2: 1$. Appearance of the $\mathrm{Ti}$ (III) state is typical for samples treated in hydrogen plasma and suggests that oxygen vacancies are formed to maintain electrostatic balance. ${ }^{20}$

Concerning the oxygen region, the registered O1s signal could be fit by two single peaks located at 530.30 and $531.11 \mathrm{eV}$. The highest results from lattice oxygen $\mathrm{Ti}^{\mathrm{i}} \mathrm{O}^{42}$ and is located at lower binding energy when compared with the pure sample. This probably results from a change in the oxidation state of partial titania species linked with oxygen atoms. The second peak found at $531.11 \mathrm{eV}$ could be attributed to oxygen vacancy Ti(III) type surface states. ${ }^{43}$ According to Wang et al. ${ }^{44}$ oxygen vacancies have a critical role in visible light absorption, and therefore the absorbance ability of $\mathrm{H}-\mathrm{TiO}_{2}$ is improved in comparison with pure $\mathrm{TiO}_{2}$.

As was registered for pure $\mathrm{TiO}_{2}$, a signal assigned to carbon species was also found in the hydrogenated sample. The C1s spectra were deconvoluted into three singlets with maxima located at $284.81 \mathrm{eV}, 286.03 \mathrm{eV}$, and $289.22 \mathrm{eV}$. The first peak is typical of $\mathrm{C}-\mathrm{C}$ bonds. According to the literature, the presence of such carbon species results from surface contamination originating from an anodization process performed in an organic electrolyte ${ }^{1}$ or from the XPS instrument itself. ${ }^{45}$ The second and third signal could be assigned to carbon linked to oxygen by single ${ }^{46}$ and double bonds, ${ }^{47}$ respectively.
Table 1 Binding energies of core levels: Ti2p, O1s, and C1s elements present in hydrogenated titania nanotube arrays

\begin{tabular}{|c|c|c|c|}
\hline Orbital & Symbol & $E_{\mathrm{bin}} / \mathrm{eV}$ & at $\%$ \\
\hline \multirow[t]{3}{*}{$\mathrm{C} 1 \mathrm{~s}$} & $\mathrm{~A}$ & 284.81 & 10.31 \\
\hline & B & 286.33 & 3.00 \\
\hline & $\mathrm{C}$ & 289.22 & 1.29 \\
\hline \multirow[t]{4}{*}{ Ti2p } & $\mathrm{Ti}^{2} \mathrm{p}_{3 / 2} \mathrm{~A}$ & 459.07 & 23.62 \\
\hline & Ti $2 p_{1 / 2} \mathrm{~A}$ & 464.79 & - \\
\hline & $\mathrm{Ti} 2 \mathrm{p}_{3 / 2} \mathrm{~B}$ & 457.20 & 1.66 \\
\hline & $\mathrm{Ti} 2 \mathrm{p}_{1 / 2} \mathrm{~B}$ & 462.62 & - \\
\hline \multirow[t]{2}{*}{ O1s } & A & 530.30 & 40 \\
\hline & B & 531.11 & 20.05 \\
\hline
\end{tabular}

As mentioned, the series of XPS measurements were performed with simultaneous etching of composite layers (see Fig. $\mathrm{S} 4 \dagger$ ). At the surface area, where polymer covers $\mathrm{TiO}_{2} \mathrm{NT}$, signals attributed to oxygen and sulfur atoms reach their maximum values. After subsequent etching of $\mathrm{H}-\mathrm{TiO}_{2} \mathrm{NTs} /$ pEDOT:PSS, the atomic contents of $\mathrm{S}$ and $\mathrm{O}$ decrease with simultaneous increase of signal attributed to titania species. However, from the $3 \mathrm{~h}$ up to the end of the etching procedure, the atomic contents of $\mathrm{S}, \mathrm{Ti}$, and $\mathrm{O}$ do not change significantly, which clearly reveals that the pEDOT:PSS matrix fills in the interior of the $\mathrm{H}-\mathrm{TiO}_{2} \mathrm{NTs}$ layer and a three dimensional inorganic-organic interface is formed.

\section{Electropolymerization analysis}

As mentioned in the experimental section, deposition of conducting polymer was realized via potentiostatic electrochemical polymerization. The chronoamperometry curves for electropolymerization of pEDOT:PSS over a pure and hydrogenated titania layer are shown in Fig. 5. A huge difference was observed in the current density value and its shape. In the case of hydrogenated titania, an increase in the current is registered at the initial stage. Within about $15 \mathrm{~s}$ a current plateau is achieved, typical of already overlapped nuclei of a new phase. The whole polymerization process is realized within only $60 \mathrm{~s}$, which may be a result of a short nucleation time. ${ }^{\mathbf{8 , 4 9}}$ In the case of pure titania, an exponential current decay is observed. The shape of the current, which changes with time, is typical of early
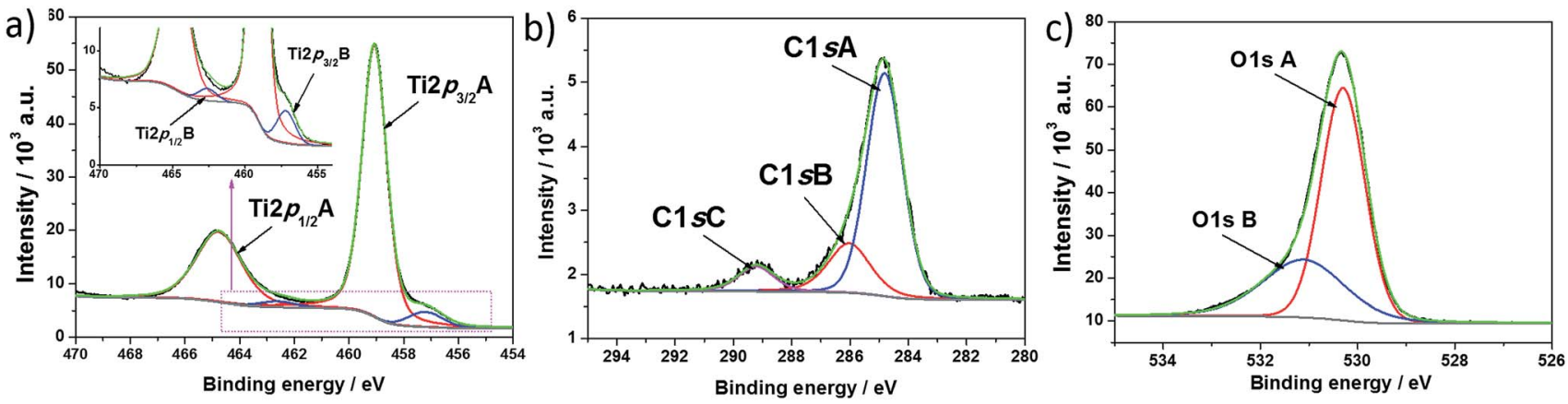

Fig. 4 High resolution XPS spectra recorded at (a) titanium, (b) carbon, and (c) oxygen for $\mathrm{H}-\mathrm{TiO}_{2}$ nanotubes. 


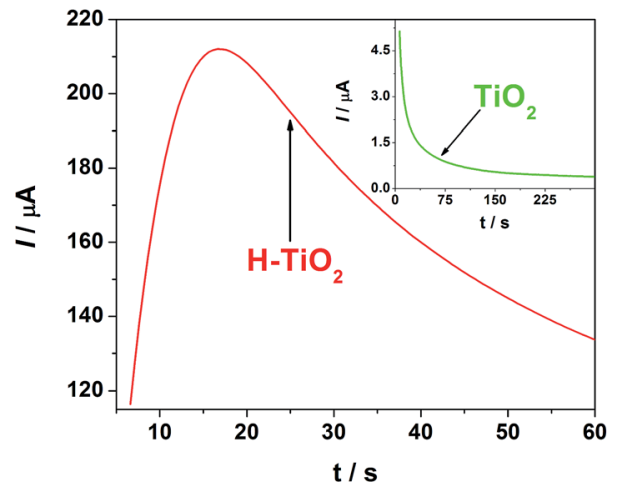

Fig. 5 Current time transients for pEDOT:PSS electropolymerization at pure and hydrogenated $\mathrm{TiO}_{2} \mathrm{NTs}$ registered at $E=1.6 \mathrm{Vvs}$. Ag/AgCl/ $0.1 \mathrm{M} \mathrm{KCl}$ (electrolyte: aqueous solution of $0.1 \mathrm{M} \mathrm{NaPSS}$ and $0.001 \mathrm{M}$ EDOT).

stages of polymerization before nuclei are overlapped. ${ }^{50}$ At a potential of $1.6 \mathrm{~V}$ vs. $\mathrm{Ag} / \mathrm{AgCl} / 0.1 \mathrm{M} \mathrm{KCl}$, the electropolymerization occurs inefficiently on pristine titania and an extended time range of pEDOT:PSS deposition is needed for polymer film formation. ${ }^{51}$ Despite electropolymerization on pure $\mathrm{TiO}_{2}$ being carried out for an hour, uniform polymer deposition was not achieved, meaning comparison of electrochemical and photoelectrochemical properties between $\mathrm{H}-$ $\mathrm{TiO}_{2} /$ pEDOT:PSS and $\mathrm{TiO}_{2} /$ pEDOT:PSS composites was not possible.

In contrast, electrode oxidation on $\mathrm{H}-\mathrm{TiO}_{2}$ is fully realized by charge propagation and leads to formation of a conducting polymer film. Thus, it is suggested that the hydrogenation process activates the titania surface and facilitates monomer absorption and nucleation, with the entire electropolymerization occurring efficiently. However, further studies are required to prove changes in adsorption conditions on plasma treatment. At this stage of our investigation it can be postulated that facilitation results from a significant impedance decrease resulting from hydrogenation.

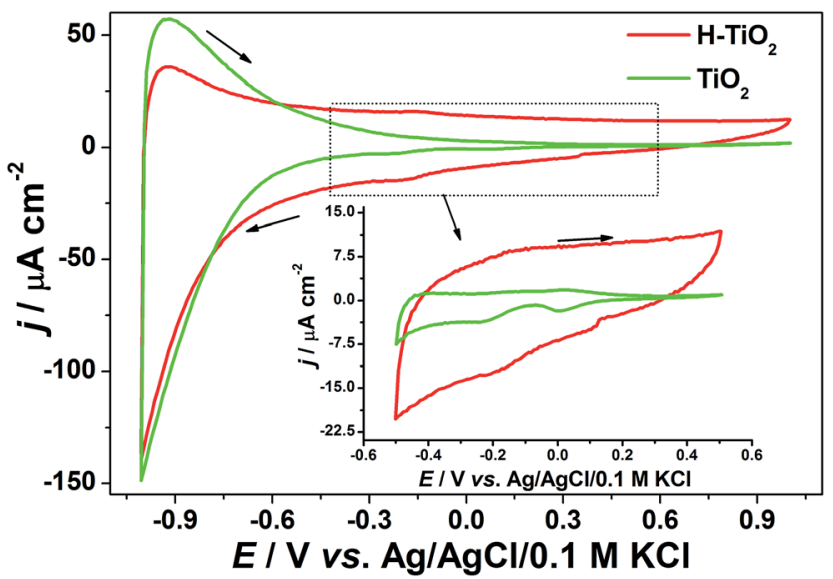

Fig. 6 Cyclic voltammetry curves recorded for pristine and hydrogenated titania immersed in $0.5 \mathrm{M} \mathrm{K}_{2} \mathrm{SO}_{4}, v=50 \mathrm{mV} \mathrm{s}^{-1}$.

\section{Electrochemical characterization of hydrogenated titania}

The cyclic voltammetry curves registered for pure and hydrogenated titania are given in Fig. 6. In the investigated potential range, both samples deliver obvious pseudocapacitive characteristics that could be attributed to oxidation/reduction of surface hydroxyl groups. ${ }^{20}$ The observed low electrochemical activity of unmodified titania could be a result of its high resistance. ${ }^{52}$ The reduction peaks at around $0 \mathrm{~V} v s$. $\mathrm{Ag} / \mathrm{AgCl} / 0.1$ $\mathrm{M} \mathrm{KCl}$ can be ascribed as an activity of intraband gap localized states. ${ }^{53}$ In contrast with pure $\mathrm{TiO}_{2}$ NTs on hydrogen plasma treatment, the charging current density increases significantly, which is related to the capacitance enhancement and conductivity improvement. ${ }^{20,54}$

To investigate sample resistance, electrochemical impedance measurements were conducted on pristine and hydrogenated titania materials. Spectra were collected at the rest potential as well as in the wide potential range. Fig. 7 shows that the spectra exhibit at least two time constants attributed to the response of the space charge layer in series with the Helmholtz layer at the electrolyte side. This concept state was proposed as a base for an analysis of obtained spectra and an electric equivalent circuit (EEQC), given in Fig. S5† with the value of each parameter listed in Table S1. $\uparrow$ The same EEQC has been previously applied for pure and non-metal doped titania, ${ }^{27}$ and is similar to that proposed by other researchers. ${ }^{55,56}$ The goodness of the performed fitting procedure was in the order of $10^{-5}$ (the meaning of each element is given in a previous report ${ }^{27}$ and also in ESI $\dagger$ ).

When comparing the spectra registered at the open circuit potential $\left(E_{\mathrm{OCP}}\right)$, an enormous decrease in $R_{1}$ resistance of $\mathrm{H}-$ $\mathrm{TiO}_{2}$ in comparison with an untreated sample is observed, which suggests that charge transfer processes between tubular film and titanium support will be facilitated. The value of the $\mathrm{CPE}_{1}$ element does not change much on hydrogenation, whereas the value of the $\mathrm{CPE}_{2}$ element increases by two orders of magnitude. The inconsiderable increase of capacitance

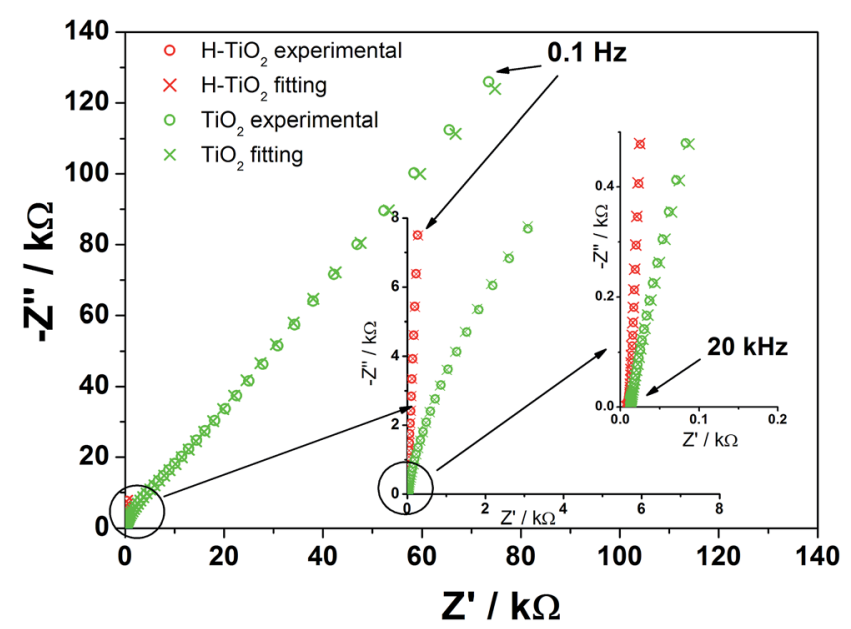

Fig. 7 Impedance spectra registered for $\mathrm{TiO}_{2}$ and $\mathrm{H}-\mathrm{TiO}_{2}$ nanotubes at the open circuit potential: $E_{\mathrm{OCP}}\left(\mathrm{TiO}_{2} \mathrm{NTS}\right)=+0.33 \mathrm{~V}, E_{\mathrm{OCP}}(\mathrm{H}-$ $\left.\mathrm{TiO}_{2} \mathrm{NTs}\right)=-0.09 \mathrm{~V} v \mathrm{~s}$. $\mathrm{Ag} / \mathrm{AgCl} / 0.1 \mathrm{M} \mathrm{KCl}$ (electrolyte: $0.5 \mathrm{M} \mathrm{K}_{2} \mathrm{SO}_{4}$ ). 
attributed to the bottom, planar oxide film is related to its low real surface area and electrochemical activity. On the other hand, enlargement of the tubular oxide capacity denoted for $\mathrm{H}-$ $\mathrm{TiO}_{2}$ could be explained in terms of higher donor concentration and anodic shift of the flatband potential when compared with pure $\mathrm{TiO}_{2}{ }^{53}$ (as shown later).

Analysis of the impedance spectra recorded in the wide potential range allows for further analysis according to the Mott-Schottky relation, given as:

$$
\frac{1}{C^{2}}=\left(\frac{2}{q \varepsilon \varepsilon_{0} N_{\mathrm{D}}}\right)\left(E-E_{\mathrm{fb}}-\frac{k T}{q}\right)
$$

where $C$ is real capacity of the space charge layer, $q$ - elementary charge, $\varepsilon_{0}$ - vacuum permittivity, $\varepsilon$ - dielectric constant, $N_{\mathrm{D}}-$ concentration of donors, $E$ - applied potential bias, $E_{\mathrm{fb}}$ - flatband potential, $k$ - Boltzmann's constant, and $T$ - absolute temperature. The run of the Mott-Schottky plot for pristine and hydrogenated titania is shown in Fig. S6; $†$ its shape was discussed in detail in our previous work. ${ }^{25}$ The nonlinear relation in the range between +0.6 and -0.9 occurs because of an intrinsic electronic state ${ }^{53}$ which could result from charging of bulk or surface states ${ }^{57}$ or irregular inhomogeneous distribution of $\mathrm{O}^{2-}$ ions. ${ }^{58}$ The positive slope exhibited by both titania samples is characteristic of n-type semiconductors and can be determined from the intercept with $E$-axis flatband potential. ${ }^{59}$ For pure titania, $E_{\mathrm{fb}}$ equals $0.2 \mathrm{~V} v s$. $\mathrm{Ag} / \mathrm{AgCl} / 0.1 \mathrm{M} \mathrm{KCl}$, whereas in the case of $\mathrm{H}-\mathrm{TiO}_{2}$, the $E_{\mathrm{fb}}$ value is cathodically shifted to $+0.1 \mathrm{~V} v s$. $\mathrm{Ag} / \mathrm{AgCl} / 0.1 \mathrm{M} \mathrm{KCl}$. Such an upward shift of flatband potential could lead to larger band bending at the surface of $\mathrm{H}-\mathrm{TiO}_{2}$, and could facilitate separation of charge carriers at the electrode/ electrolyte interface, ${ }^{60}$ which would affect considerably the overall photoconversion efficiency. A difference between slopes of the two plots is also observed, indicating a huge disparity of donor densities in pure and modified titania. The carrier density $N_{\mathrm{D}}$ can be calculated from the following equation:

$$
N_{\mathrm{D}}=\left(2 / e \varepsilon \varepsilon_{0}\right)\left[\frac{\mathrm{d} C^{-2}}{\mathrm{~d} E}\right]^{-1}
$$

when the following values are taken into account: $e=1.6 \times$ $10^{-19}, \varepsilon_{0}=8.86 \times 10^{-14} \mathrm{~F} \mathrm{~cm}^{-1}$, and $\varepsilon=31$ for anatase. ${ }^{61}$ The calculated donor densities of $\mathrm{TiO}_{2} \mathrm{NTs}$ and $\mathrm{H}-\mathrm{TiO}_{2} \mathrm{NTs}$ are 6.45 $\times 10^{20}$ and $2.27 \times 10^{23} \mathrm{~cm}^{-3}$, respectively. Despite the MottSchottky plot not allowing for estimation of the absolute value of $N_{\mathrm{D}}{ }^{62}$ the significant difference shows that upon hydrogen plasma treatment donor the density is greatly enhanced when compared with that of unmodified samples. Such a change was observed for other hydrogenated titania and is commonly attributed to introduction of substantial oxygen vacancies that are regarded as electron donors in titania. ${ }^{63,64}$ Therefore, $\mathrm{H}-\mathrm{TiO}_{2}$ is characterized as having better conductivity, and therefore improved charge separation and transport could be expected within the material.

\section{Electrochemical properties of the composite material}

Electrochemical studies were also conducted on the composite material, with cyclic voltammetry and electrochemical impedance spectroscopy measurements performed. CV curves and registered impedance spectra at the open circuit potential are shown in Fig. 8 and 9, respectively. The working electrode was polarized from rest potential in the anodic direction up to $0.7 \mathrm{~V}$ and back up to $-0.7 \mathrm{~V} v$ s. $\mathrm{Ag} / \mathrm{AgCl} / 0.1 \mathrm{M} \mathrm{KCl}$. Among tested materials, only the composite electrode exhibits symmetrical cathodic/anodic current peaks at $+0.15 \mathrm{~V} v s$. Ag/AgCL/0.1 M KCl and significantly higher current density when compared with that recorded for $\mathrm{H}-\mathrm{TiO}_{2}$ nanotube or pure polymer film, illustrating improved electrochemical activity. The electrochemical impedance measurements performed on the composite material show its hybrid nature between pure polymeric and titania material. The shape of registered spectra for $\mathrm{H}-\mathrm{TiO}_{2} \mathrm{NT} / \mathrm{pEDOT}$ :PSS is similar to that of pEDOT:PSS alone, ${ }^{65}$ but the resistance is higher because of the presence of titania network. The EEQC proposed for titania samples was modified by the introduction of an additional arrangement of elements attributed to the polymer part (see Fig. S7 $\dagger$ ). The goodness of the proposed fitting equals $6.5 \times 10^{-5}$, and the values for each element of EEQC are listed in Table S2. $\uparrow$ When conducting polymer is present, the electronic conductivity of the whole composite results not only from the titania network, but also from charge propagation along the oxidized pEDOT chains. The action accruing at the oxidized chains could proceed according to the reactions: ${ }^{66}$

$$
\mathrm{pEDOT}^{x+}+x \mathrm{e}^{-}+\mathrm{PSS}^{-} \rightarrow \mathrm{pEDOT}^{+} x\left(\mathrm{PSS}^{-}\right)_{\mathrm{sol}}
$$

and/or

$$
\operatorname{pEDOT}^{x+}\left(\mathrm{PSS}^{-}\right)_{x}+x \mathrm{e}^{-}+\mathrm{C}^{+} \rightarrow \operatorname{pEDOT}\left(\mathrm{PSS}^{-}\right)_{x}\left(\mathrm{C}^{+}\right)_{x}
$$

Interpretation of the majority of elements was given in the section concerning impedance of $\mathrm{H}-\mathrm{TiO}_{2} \mathrm{NTs}$. Here, $R_{3}$ is attributed to resistance at the $\mathrm{TiO}_{2}$ nanotube/polymer interface and $\mathrm{CPE}_{3}$ reflects the pseudocapacitance of pEDOT:PSS. ${ }^{67}$ Because of the capacitive character exhibited by infiltrated polymer, the overall capacitance of the composite increases, which is in agreement with the shape of cyclic voltammetry curves. In summary, the registered impedance spectra show the double nature of $\mathrm{H}-\mathrm{TiO}_{2} \mathrm{NTs} / \mathrm{pEDOT}$ :PSS material and the

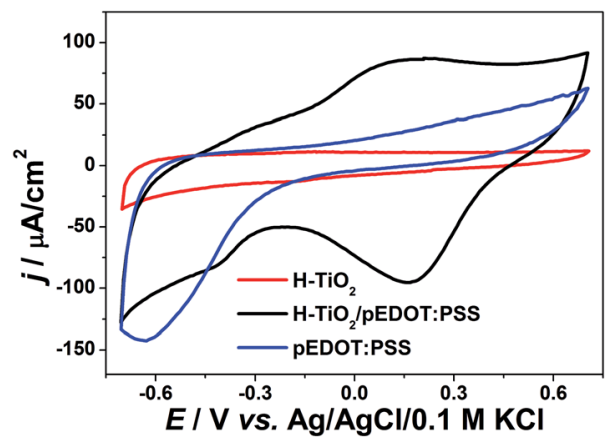

Fig. 8 Cyclic voltammetry curves of composite material $\mathrm{H}-\mathrm{TiO}_{2} \mathrm{NTs} /$ pEDOT:PSS and its pure counterparts (electrolyte: $0.5 \mathrm{M} \mathrm{K}_{2} \mathrm{SO}_{4}, \mathrm{~V}=50$ $\mathrm{mV} \mathrm{s}^{-1}$. 


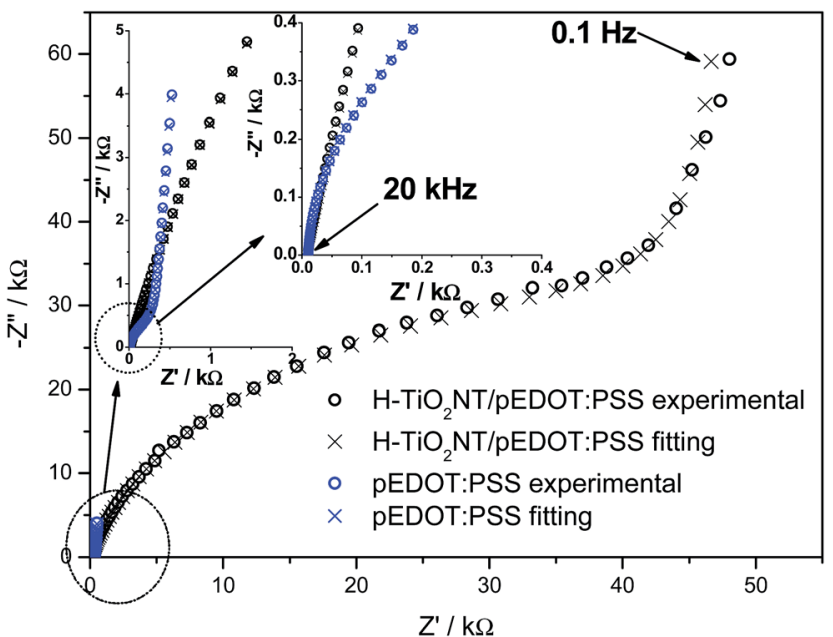

Fig. 9 Impedance spectra registered for pEDOT:PSS and composite material: $\mathrm{H}-\mathrm{TiO}_{2} \mathrm{NTs} / \mathrm{pEDOT}$ :PSS at the open circuit potential: $E_{\mathrm{OCP}}$ (pEDOT:PSS $)=+0.27 \mathrm{~V}, E_{\mathrm{OCP}}\left(\mathrm{H}-\mathrm{TiO}_{2} \mathrm{NTs} / \mathrm{pEDOT}: \mathrm{PSS}\right)=+0.24 \mathrm{~V}$ vs $\mathrm{Ag} / \mathrm{AgCl} / 0.1 \mathrm{M} \mathrm{KCl}$ (electrolyte: $0.5 \mathrm{M} \mathrm{K}_{2} \mathrm{SO}_{4}$ ).

impact of polymer is evident on improvement of composite electric properties. The decrease in overall resistance could be important in transfer of photogenerated charge carriers.

\section{Photoelectrochemical activity}

Photoelectrochemical properties of electrodes were investigated using the chronoamperometry technique recorded at constant potential under "chopped" simulated solar light illumination. The materials obtained were anodically polarized $(E=0.5 \mathrm{~V} v s$. $\mathrm{Ag} / \mathrm{AgCl} / 0.1 \mathrm{M} \mathrm{KCl}$ ) and immersed in $0.5 \mathrm{M} \mathrm{K}_{2} \mathrm{SO}_{4}$ aqueous electrolyte without any additives acting as a hole capturer. The chronoamperometry curves of $\mathrm{H}-\mathrm{TiO}_{2} \mathrm{NTs} / \mathrm{pEDOT}$ :PSS, and as reference: $\mathrm{H}-\mathrm{TiO}_{2} \mathrm{NTs}$, $\mathrm{TiO}_{2} \mathrm{NTs}$, and pEDOT:PSS layer, are presented in Fig. 10, and the values of photocurrent density registered after $8 \mathrm{~min}$ of measurements are listed in Table 2.

Among all tested materials, conducting polymer alone exhibits the lowest photoactivity that is typical of neat PEDOT. ${ }^{8,26}$ For $\mathrm{H}^{-}$
$\mathrm{TiO}_{2}$ and $\mathrm{TiO}_{2}$ nanotubes, after 8 min of measurement duration, the photocurrent densities on UV-Vis irradiation reached 54 and $42 \mu \mathrm{A} \mathrm{cm}^{-2}$, respectively. Thus, a hydrogenated sample is characterized with almost 30\% enhancement that results from a higher absorbance ability and improved electric properties when compared with pristine titania. It should also be noted that, despite hydrogenation treatment, titania response on illumination is stable and no current diminution is observed. After deposition of polymer, the obtained composite material is characterized by remarkable photoactivity, reaching $c a .106 \mu \mathrm{A} \mathrm{cm}^{-2}$ under UV-Vis illumination and $4.9 \mu \mathrm{A} \mathrm{cm}^{-2}$ when the electrode is illuminated by vis radiation. The observed enhancement is significantly higher under UV-Vis and Vis irradiation than that described for the heterojunction composed of pEDOT:PSS and titanium dioxide nanoparticles. ${ }^{68}$ Improved photoactivity of $\mathrm{H}^{-}$ $\mathrm{TiO}_{2} \mathrm{NTS} /$ pEDOT:PSS in comparison with its pure counterparts results from formation of a $\mathrm{p}-\mathrm{n}$ heterojunction when appropriate alignment of conduction and valence band positions of both ptype and n-type semiconductors allows for charge separation at the organic/inorganic heterojunction. ${ }^{69}$ According to Haring et al. ${ }^{70}$ in the case of conducting polymer- $\mathrm{TiO}_{2}$ composite, there are three criteria for efficient hybrid bulk heterojunction: (a) Fermi level of $\mathrm{TiO}_{2}$ to be close to its conduction band, (b) the difference between conduction band and LUMO should equal at least $0.3 \mathrm{eV},{ }^{71}$ and (c) Fermi level should be higher when compared with energy polarons level in the separated materials. ${ }^{72}$

On infiltration of titania by pEDOT:PSS, charge transfer from $\mathrm{TiO}_{2}$ would create positive polarons in the polymer matrix,

Table 2 Photocurrent values obtained for investigated electrode materials under UV-Vis and vis illumination after $500 \mathrm{~s}$ of measurement

\begin{tabular}{lrl}
\hline Electrode material & $j(\mathrm{UV}-\mathrm{Vis}) / \mu \mathrm{A} \mathrm{cm}$ & $j(\mathrm{Vis}) / \mu \mathrm{A} \mathrm{cm}^{-2}$ \\
\hline $\mathrm{H}^{-\mathrm{TiO}_{2} \text { NTs/pEDOT:PSS }}$ & 106 & 4.9 \\
$\mathrm{H}^{-T i O} \mathrm{NTs}_{2}$ NTs & 54 & 0.9 \\
$\mathrm{TiO}_{2}$ NTs & 42 & 0.8 \\
pEDOT:PSS & 2 & 0.7
\end{tabular}
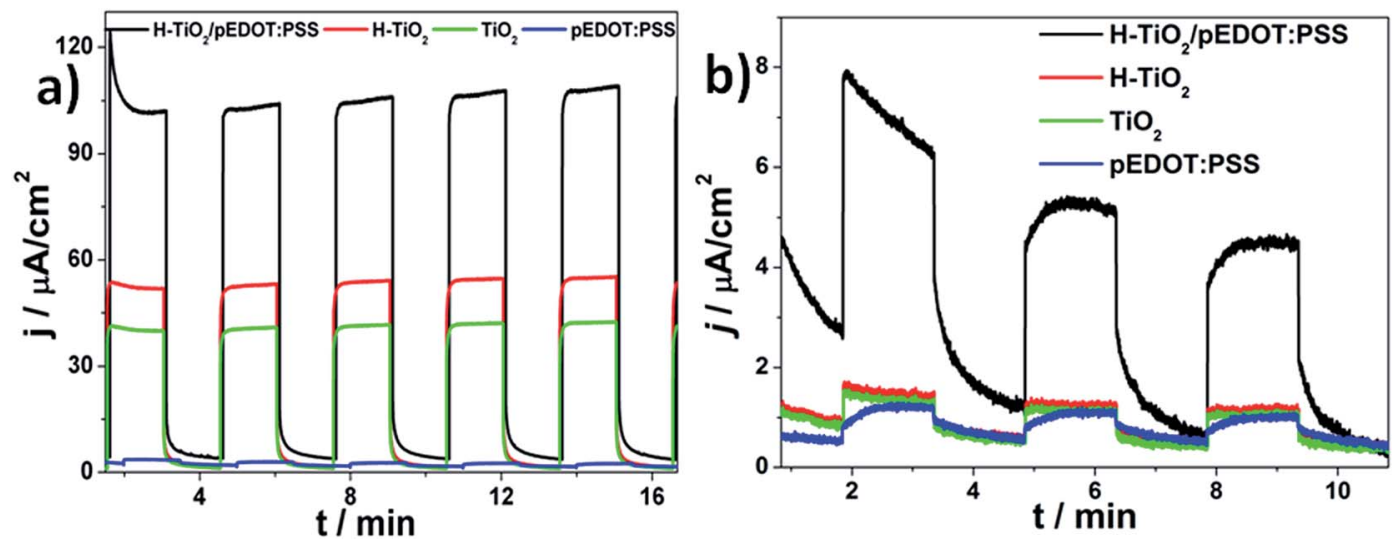

Fig. 10 Transient photocurrent response of pure and hydrogenated titania, pure polymer, and $\mathrm{H}-\mathrm{TiO}{ }_{2} \mathrm{NT} / \mathrm{pEDOT}$ :PSS composite material registered under (a) UV-Vis and (b) vis illumination at $0.5 \mathrm{~V} v$ s. $\mathrm{Ag} / \mathrm{AgCl} / 0.1 \mathrm{M} \mathrm{KCl}$ (electrolyte: $0.5 \mathrm{M} \mathrm{K}_{2} \mathrm{SO}_{4}$ ). 
resulting in formation of an electric field in the polymer that would assist photoelectron injection. Furthermore, in the presence of oxygen vacancies, the excess of negative charge on Ti(III) sites leads to formation of occupied deep traps below the conduction band. ${ }^{73}$ As demonstrated, unlike pristine titania, the proposed hydrogenation treatment of $\mathrm{TiO}_{2} \mathrm{NTs}$ results in partial reduction of $\mathrm{Ti}$ (Iv) to $\mathrm{Ti}$ (III) and a decrease of the Fermi level of the flatband electrode, which could allow for spontaneous electron transfer from pEDOT:PSS to $\mathrm{H}-\mathrm{TiO}_{2} \mathrm{NTs}$. It should be noted that it is not just the favourable conditions for formation of electron polarons in $\mathrm{H}-\mathrm{TiO}_{2} \mathrm{NTs} / \mathrm{pEDOT}$ :PSS that are responsible for photocurrent increase of in the $\mathrm{p}-\mathrm{n}$ junction. Other factors are also important in enhancement of photoconversion efficiency, such as improved absorbance ability in the visible range when compared with titania NTs or the pEDOT:PSS layer, and ordered morphology of the titania layer facilitating electron percolation and providing a large contact area for uniform distribution of polymer on the surface as well as along the tubes. ${ }^{74}$

Additionally, stability of $\mathrm{H}-\mathrm{TiO}_{2} \mathrm{NTs} /$ pEDOT:PSS on prolonged illumination was also verified (see Fig. S8†). In contrast with our previous results on the $\mathrm{TiO}_{2} \mathrm{NTs} / \mathrm{pEDOT}$ :PSS heterojunction $^{\mathbf{1 4}}$ or other titania-polymer heterojunctions, ${ }^{75,76}$ even over 50 min of illumination, no drop was observed in photoactivity. It should also be noted that on long-term irradiation the current density value slightly increases, because of oxidation of the polymer layer induced by photon absorption. The change in oxidation has an impact on the position of energy levels, ${ }^{77}$ and thus charge transfer at the organic/inorganic interface could proceed more efficiently. Electrochemical stability of the composite material was confirmed before and after illumination using cyclic voltammetry measurements. As shown in Fig. S6b $\uparrow$ the shape of the CV curve is unchanged, confirming the excellent photoresistivity of the organic-inorganic heterojunction.

\section{Conclusions}

In this study, the conducting polymer pEDOT:PSS was used as an organic sensitizer to form three-dimensional heterojunctions with ordered titania nanotubes. Infiltration of titania with the polymer was realized via electropolymerization carried out on titania electrode followed by treatment in hydrogen plasma. Spectroscopic and electrochemical measurements show that the proposed plasma processing leads to formation of $\mathrm{Ti}$ (III) species, enhancement of absorbance ability in the visible range, and conductivity and capacitance improvement when compared with pristine $\mathrm{TiO}_{2}$. On the basis of the impedance spectra analysis, flatband potential and donor density for $\mathrm{TiO}_{2}$ and $\mathrm{H}-\mathrm{TiO}_{2} \mathrm{NTs}$ were estimated to be $E_{\mathrm{fb}}=-0.16 \mathrm{~V} v s$. $\mathrm{Ag} / \mathrm{AgCl} / 0.1 \mathrm{M} \mathrm{KCl}, N_{\mathrm{D}}=$ $6.45 \times 10^{20} \mathrm{~cm}^{-3}$, and $E_{\mathrm{fb}}=+0.11 \mathrm{~V}$ vs. $\mathrm{Ag} / \mathrm{AgCl} / 0.1 \mathrm{M} \mathrm{KCl}$ and $N_{\mathrm{D}}=2.27 \times 10^{23} \mathrm{~cm}^{-3}$, respectively. Detailed elemental analysis has shown that hydrogen plasma facilitates uniform deposition of polymer matrix resulting in high surface area of the organicmetal oxide interface. The obtained composite material exhibits much higher capacitive current when compared with its pure counterparts, and the registered impedance spectra reflect its duplex polymer-metal oxide nature. Appropriate alignment of energy levels of $\mathrm{p}$ - and n-elements of the $\mathrm{H}-\mathrm{TiO}_{2} \mathrm{NTs} / \mathrm{pEDOT}$ :PSS heterojunction results in photocurrent density of $106 \mu \mathrm{A} \mathrm{cm}^{-2}$ under UV-vis and 4.9 under vis irradiation, approximately 2 and 5.6 times higher, respectively, than that registered for $\mathrm{H}-\mathrm{TiO}_{2}$. To summarize, an $\mathrm{H}-\mathrm{TiO}_{2} \mathrm{NTs} / \mathrm{pEDOT}$ PSS composite, offering the possibility of formation of a large $\mathrm{p}-\mathrm{n}$ heterojunction, is as an attractive material for design of photovoltaic cells.

\section{Acknowledgements}

This work received financial support from the Polish National Science Centre: Grant No. 2012/07/D/ST5/02269.

\section{References}

1 P. Roy, S. Berger and P. Schmuki, Angew. Chem., 2011, 50, 2904.

2 D. Kowalski, D. Kim and P. Schmuki, Nano Today, 2013, 8, 235.

3 D. Wang, Y. Liu, B. Yu, F. Zhou and W. Liu, Chem. Mater., 2009, 21, 1198.

4 J. M. Macak, H. Tsuchiya, A. Ghicov, K. Yasuda, R. Hahn, S. Bauer and P. Schmuki, Curr. Opin. Solid State Mater. Sci., 2007, 11, 3.

5 B. Chen, J. Hou and K. Lu, Langmuir, 2013, 29, 5911.

6 K. Siuzdak, M. Abbas, L. Vignau, M. Devynck, G. Dubacheva and A. Lisowska-Oleksiak, J. Appl. Phys., 2012, 112, 123110.

7 Q. Chen and D. Xu, J. Phys. Chem. C, 2009, 113, 6310.

8 J. Boucle, P. Ravirajan and J. Nelson, J. Mater. Chem., 2007, 17, 3141.

9 Y. Jia, P. Xiao, H. He, J. Yao, F. Liu, Z. Wang and Y. Li, Appl. Surf. Sci., 2012, 258, 6627.

10 J. Luo, Y. Ma, H. Wang and J. Chen, Electrochim. Acta, 2015, $167,119$.

11 P. M. Dziewoński and M. Grzeszczuk, Electrochim. Acta, 2010, 55, 336.

12 G. F. Samu, C. Visy, K. Rajeshwar, S. Sarker, V. R. Subramanian and C. Janáky, Electrochim. Acta, 2015, 151, 467.

13 S. H. Mujawar, S. B. Ambade, T. Battumur, R. B. Ambade and S. H. Lee, Electrochim. Acta, 2011, 56, 4462.

14 Y. Jia, P. Xiao, H. He, J. Yao, F. Liu, Z. Wang and Y. Li, Appl. Surf. Sci., 2012, 258, 6627.

15 K. Siuzdak, M. Sawczak and A. Lisowska-Oleksiak, Solid State Ionics, 2015, 271, 56.

16 H. Du, Y. Xie, C. Xia, W. Wang and F. Tian, New J. Chem., 2014, 38, 1284.

17 C. Janaky, N. R. de Tacconi, W. Chanmanee and K. Rajeshwar, J. Phys. Chem. C, 2012, 116, 19145.

18 D. Kowalski and P. Schmuki, Chem. Commun., 2010, 46, 8585.

19 S. Xie, M. Gan, L. Ma, Z. Li, J. Yan, H. Yin, X. Shen, Z. Xu, J. Zhang and J. Hu, Electrochim. Acta, 2011, 56, 4462.

20 C. Janaky and K. Rajeshwar, Prog. Polym. Sci., 2015, 43, 96.

21 J. Chen, Z. Xia, H. Li, Q. Li and Y. Zhang, Electrochim. Acta, 2014, 120, 408.

22 X. Lu, G. Wang, T. Zhai, M. Yu, J. Gan, Y. Tong and Y. Li, Nano Lett., 2012, 12, 1690. 
23 H. Wu, C. Xu, J. Xu, L. Lu, Z. Fan, X. Chen, Y. Song and D. Li, Nanotechnology, 2013, 24, 455401.

24 K. Siuzdak, M. Szkoda, M. Sawczak and A. LisowskaOleksiak, New J. Chem., 2015, 39, 2741.

25 D. Kowalski and P. Schmuki, RSC Adv., 2013, 3, 2154.

26 C. Janáky, G. Bencsik, A. Racz and C. Visy, Langmuir, 2010, 26, 13697.

27 K. Siuzdak, M. Szkoda, M. Sawczak, A. Lisowska-Oleksiak, J. Karczewski and J. Ryl, RSC Adv., 2015, 5, 50379.

28 X. Chen and S. S. Mao, Chem. Rev., 2007, 107, 2891.

29 A. Lisowska-Oleksiak, A. P. Nowak, M. Wilamowska, M. Sikora, W. Szczerba and C. Kapusta, Synth. Met., 2010, 160, 1234.

30 S. Garreau, G. Louarn and J. Buisson, Macromolecules, 1999, 32, 6807.

31 Z. Wang, C. Y. Yang, T. Q. Lin, H. Yin, P. Chen, D. Y. Wan, F. F. Xu, F. Q. Huang, J. H. Lin, X. M. Xie and M. H. Jiang, Energy Environ. Sci., 2013, 6, 3007.

32 X. B. Chen, L. Liu, P. Y. Yu, S. S. Mao, X. Chen, L. Liu, Y. Y. Peter and S. S. Mao, Science, 2011, 331, 746.

33 A. Sasinka, T. Singh, S. Wang, S. AMthur and R. Kraehnert, J. Vac. Sci. Technol., A, 2015, 33, 01A152.

34 E. M. Samsudin, S. B. A. Hamid, J. C. Juan, W. J. Basirun and A. E. Kandjani, Appl. Surf. Sci., 2015, 359, 883.

35 Y. Mizukoshi, N. Ohtsu and N. Masahashi, Appl. Surf. Sci., 2013, 283, 1018.

36 Z. Wang, C. Yang, T. Lin, H. Yin, P. Chen, D. Wan and M. Jiang, Adv. Funct. Mater., 2013, 23, 5444.

37 C. Janáky, G. Bencsik, A. Rácz, C. Visy, N. R. de Tacconi, W. Chanmanee and K. Rajeshwar, Langmuir, 2010, 26, 13697.

38 A. P. Nowak, M. Wilamowska and A. Lisowska-Oleksiak, J. Solid State Electrochem., 2010, 14, 263.

39 K. Siuzdak, M. Szkoda, A. Lisowska-Oleksiak, K. Grochowska, J. Karczewski and J. Ryl, Appl. Surf. Sci., 2015, 357, 942.

40 Q. Zhang, Y. Li, E. A. Ackerman, M. Gajdardziska-Josifovska and H. Li, Appl. Catal., A, 2011, 400, 195.

41 X. Jiang, Y. Zhang, J. Jiang, Y. Rong, Y. Wang, Y. Wu and C. Pan, J. Phys. Chem. C, 2012, 116, 22619.

42 X. Zhou, B. Jin, S. Zhang, H. Wang, H. Yu and F. Peng, Electrochem. Commun., 2012, 19, 127.

$43 \mathrm{X} . \mathrm{Wu}, \mathrm{C} . \mathrm{Xu}, \mathrm{J} . \mathrm{Xu}, \mathrm{L} . \mathrm{Lu}, \mathrm{Z}$. Fan, X. Chen, Y. Song and D. Li, Nanotechnology, 2013, 24, 455401.

44 G. Wang, H. Wang, Y. Ling, Y. Tang, X. Yang, R. C. Fitzmorris, C. Wang, J. Z. Zhang and Y. Li, Nano Lett., 2011, 11, 3026.

45 Y. Li, G. Ma, S. Peng, G. Lu and S. Li, Appl. Surf. Sci., 2008, 254, 6831.

46 J. Yang, H. Bai, Q. Jiang and J. Lian, Thin Solid Films, 2008, 516, 1736.

47 T. I. T. Okpalugo, P. Papakonstantinou, H. Murphy, J. McLaughlin and M. N. D. Brow, Carbon, 2005, 43, 153.

48 J. Xia, N. Masaki, K. Jiang and S. Yanagida, J. Mater. Chem., 2007, 17, 2845.

49 A. A. Alamrio and R. L. Vieira, J. Chil. Chem. Soc., 2006, 51, 971.
50 M. E. G. Lyons, Transport and kinetics in electroactive polymers, Advances in Chemical Physics: Polymeric systems, ed. I. Progogine and S. A. Rice, Wiley \& sons, 1996, vol. XCIV, p. 279.

51 M. Graczyk-Zajac, S. Y. Vassiliev, M. A. Vorotynsev and G. A. Tsirlina, J. Solid State Electrochem., 2010, 14, 2039.

52 F. Fabregat-Santiago, J. Mora-Seró, G. Garcia-Belmonte and J. Bisquert, J. Phys. Chem. B, 2003, 107, 758.

53 G. Boschloo and D. Fitzmaurice, J. Phys. Chem. B, 1999, 103, 2228.

54 H. Wu, D. Li, X. Zhu, C. Yang, D. Liu, X. Chen, Y. Song and L. Lu, Electrochim. Acta, 2014, 116, 129.

55 A. G. Muñoz, Q. Chen and P. Schmuki, J. Solid State Electrochem., 2007, 11, 1077.

56 Z. Zhang, Z. Zhou, S. Nie, H. Wang, H. Peng, G. Li and K. Chen, J. Power Sources, 2014, 267, 388.

57 D. B. Bonham and M. E. A. Orazem, J. Electrochem. Soc., 1992, 139, 127.

58 X. Wang and J. Zhao, IEEE Trans. Nanotechnol., 2014, 14, 113. 59 K. Gelderman, L. Lee and S. W. Donne, J. Chem. Educ., 2007, 84, 685.

60 C. Yang, Z. Wang, T. Lin, H. Yin, X. Lü, D. Wan and M. Jiang, J. Am. Chem. Soc., 2013, 135, 17831.

61 H. Tang, K. Prasad, R. Sanjines, P. E. Schmid and F. Levy, J. Appl. Phys., 1994, 75, 2042.

62 B. Chen, J. A. Beach, D. Maurya, R. B. Moore and S. Priya, RSC Adv., 2014, 4, 29443.

63 H. Cui, W. Zhao, C. Yang, H. Yin, T. Lin, Y. Shan, Y. Xie, H. Gu and F. Hang, J. Mater. Chem. A, 2014, 2, 8612.

64 X. Lu, G. Wang, Z. Zhai, M. Yu, J. Gan, Y. Tong and Y. Li, Nano Lett., 2012, 12, 1690.

65 A. Lisowska-Oleksiak and A. P. Nowak, Solid State Ionics, 2008, 179, 72.

66 A. Lisowska-Oleksiak and A. Kupniewska, Solid State Ionics, 2003, 157, 241.

67 H. Du, Y. Zie, C. Xia, W. Wang and F. Tian, New J. Chem., 2014, 38, 1284.

68 J. Baek, Y. Kim and E. Kim, Mol. Cryst. Liq. Cryst., 2008, 483, 275.

69 A. Arena, N. Donato, G. Saitta, G. Rizzo, G. Neri and G. Pioggia, J. Sol-Gel Sci. Technol., 2007, 43, 41.

70 A. J. Haring, S. R. Ahrenholtz and A. J. Morris, ACS Appl. Mater. Interfaces, 2014, 6, 4394.

71 M. C. Scharber, D. Wuhlbacher, M. Koppe, P. Denk, C. W. Ardauf, A. J. Heeger and C. L. Brabec, Adv. Mater., 2006, 18, 789.

72 S. Braun, W. R. Salaneck and M. Fahlman, Adv. Mater., 2009, 21, 1450.

73 C. D. Valentin, G. Pacchioni and A. Selloni, J. Phys. Chem. C, 2009, 113, 20543.

74 L. Bertoluzzi, L. Badia-Bou, F. Fabregat-Santiago, S. Gimenez and J. Bisquert, J. Phys. Chem. Lett., 2013, 4, 1334.

75 Y. Jia, P. Xiao, H. He, J. Yao, F. Liu, Z. Wang and Y. Li, Appl. Surf. Sci., 2012, 258, 6627.

76 X. Zhang, F. Peng, H. Wang, H. Yu and Y. Fang, Chem. Commun., 2011, 47, 10323.

77 Y. Xinag, M. Qian, D. Guo and G. Zhang, Chin. Phys. B, 2014, 23, 038504. 